\title{
ANÁLISE DA DEMANDA POR TRANSPORTE FERROVIÁRIO NA MICRORREGIÃO DE TOLEDO PARANÁ
}

Analysis of demand for rail transport in Toledo Paraná microregion

Análisis de la demanda de transporte ferroviario en la microregión de Toledo, Paraná.

\section{Jean Carlos de Matos ${ }^{1 *}$, Weimar Freire da Rocha Júnior ${ }^{1}$, Homero Fernandes Oliveira ${ }^{1}$, Ricardo Roberto Behr' ${ }^{2}$, Manoel João Ramos ${ }^{3}$}

${ }^{1}$ Programa de Pós-graduação Stricto Sensu em Desenvolvimento Regional \& Agronegócio, Universidade Estadual do Oeste do Paraná, Toledo, Paraná, Brasil.

${ }^{2}$ Centro de Ciências Jurídicas e Econômicas, Universidade Federal do Espírito Santo - UFES, Vitória, Espírito Santo, Brasil

${ }^{3}$ Curso de Engenharia de Produação, Faculdade de Ensino Superior de Marechal Cândido Rondon -

ISEPE/Rondon, Marechal Cândido Rondon, Paraná, Brasil

*Correspondência: SENAI - Departamento Regional do Paraná, Serviço Nacional de Aprendizagem Industrial Toledo. Rua Júlio de Castilhos-Vila Industrial CEP: 85904175 - Toledo, PR - Brasil. E-mail:

jean.matos@outlook.com

\section{RESUMO}

A existência de uma infraestrutura adequada para o transporte de cargas pode potencializar as atividades empresariais e proporcionar uma melhor qualidade de vida em uma região. Desta forma, este estudo apresenta uma análise sobre a demanda por transporte ferroviário na microrregião de Toledo/PR, com o intuito de identificar produtos favoráveis ao uso deste modal, levando em conta as relações de quantidade transportada, distância percorrida e sensibilidade ao valor do frete. A metodologia utilizada consiste no levantamento de dados primários por meio de entrevista não estruturada e observação, seguido de pesquisa documental para coleta de dados secundários, visando descrever o cenário econômico da microrregião e compreender como ocorre a movimentação de cargas atualmente. Os resultados apontam a existência de demanda para transporte ferroviário em diversos produtos, dado o dinamismo econômico, as características regionais voltadas ao agronegócio, bem como a falta de investimento neste modal, tanto para escoamento da produção quanto para a chegada de produtos que dinamizam a economia local e regional.

Palavras-chave: Transporte Ferroviário; Logística; Agronegócio.

\footnotetext{
ABSTRACT

The existence of an adequate infrastructure for the transport of cargoes can boost the business activities and provide a better quality of life in a region. Thus, this study presents an analysis of the demand for rail transport in the microregion of Toledo/PR, in order to identify favorable products to the use of this modal, considering relations of transported quantity, traveled distance and sensitivity to the value of the freight. The used methodology consists of the collection of primary data through unstructured interview and observation, followed by documentary research to collect secondary data, aiming to describe the economic scenery of the microregion and to understand how the cargo movement occurs nowadays. It was found that there is demand for rail transportation in several products, given economic dynamism, the regional characteristics geared to agribusiness, as well as the lack of investment in this modality, both for the outflow of production and for the arrival of products that dynamize the local and regional economy.
} 


\section{RESUMEN}

La existencia de una infraestructura adecuada para el transporte de cargas puede aumentar las actividades empresariales y proporcionar una mejor calidad de vida en una región. De esta manera, este estudio presenta un análisis de la demanda de transporte ferroviario en la microrregión de Toledo / PR, con el fin de identificar los productos favorables al uso de este modal, teniendo en cuenta relaciones de cantidad transportada, la distancia recorrida y la sensibilidad al valor del flete. La metodología utilizada consiste en la recolecta de datos primarios a través de la entrevista no estructurada y la observación, seguida de la investigación documental para la recopilación de datos secundarios, con el objetivo de describir la situación económica de la microrregión y entender cómo funciona el traslado de carga actualmente. Se encontró que existe una demanda de transporte ferroviario en varios productos, dado el contexto de crecimiento y desarrollo que se presenta en la microrregión y la falta de inversión en este modal, ya sea para el flujo de producción o para la llegada de productos que simplifican su economía.

Palabras clave: ferrocarril; logística; La agroindustria.

\section{INTRODUÇÃO}

O Estado do Paraná posiciona-se como forte produtor agropecuário. Em 2014, ocupou o segundo lugar em área plantada com 10,7 milhões de hectares cultivados, sendo que apenas na cultura da soja, conforme dados da Empresa Brasileira de Pesquisa Agropecuária (EMBRAPA, 2014) o Paraná plantou dois milhões de hectares, o que gerou uma produção de 17,1 milhões de toneladas, correspondente a $18 \%$ do total da produção do país que foi de 95 milhões. Um levantamento realizado pelo Departamento de Economia Rural da Secretaria de Estado da Agricultura e do Abastecimento - DERAL (2015), aponta que o Valor Bruto da Produção Rural (VBP) foi de R \$77,81 bilhões. Neste cenário, a microrregião de Toledo se destaca por liderar o VBP no estado com 1,97 bilhão em 2015, com expressiva produção de granéis agrícolas e produtos de origem animal.

Conforme Caixeta Filho (2001), se dentro da porteira o produtor brasileiro é bastante eficiente, quando a produção sai da propriedade agrícola iniciam-se as perdas de competitividade pela falta de planejamento, armazéns e escoamento, tanto para o mercado interno quanto para a exportação, devido à precária infraestrutura logística.

De maneira complementar, Coeli (2004) reitera que na cultura de soja, por exemplo, o Brasil tem os custos de produção mais baixos, se comparados com outros países produtores, porém, quando se trata do processo de armazenamento e movimentação dos grãos esse diferencial deixa de existir e o custo com as operações logísticas são extremamente maiores, o que afeta significativamente o país no fator competitividade.

Ressalta-se que existe uma preocupação em relação à competitividade da microrregião de Toledo, no mercado interno e externo, no que tange o processo de escoamento e movimentação de cargas. No ano de 2014, a microrregião produziu um volume de 1,5 milhões de toneladas de soja, deste montante, grande parte é expedida para o porto de Paranaguá para comercialização no mercado externo. Além da soja, a microrregião é o maior polo de transformação de proteína de origem animal do Estado, principalmente, frango de corte. Grande parte desta produção também tem seu destino ao mercado externo.

A Agência Nacional de Transportes Terrestres (ANTT, 2013) aponta os produtos típicos que 
apresentam características para serem transportados via modo ferroviário, tais como: produtos siderúrgicos, grãos, minério de ferro, cimento e cal, adubos e fertilizantes, derivados de petróleo, calcário, carvão mineral, clinquer e contêineres. A microrregião estudada movimenta a maioria desses produtos e, atualmente, a maior parte da movimentação, tanto expedida quanto recebida, tem sido feita via modo rodoviário. Pressupõe-se que neste modo ocorrem maiores custos e maiores gargalos na malha rodoviária e urbana.

Sendo assim, o estudo busca responder a seguinte questão: existe demanda para movimentação de cargas por meio de ferrovia na microrregião de Toledo? Para responder a essa questão, propõe-se analisar as possíveis demandas com base na indicação dos principais produtos apontados pela ANTT, bem como da necessidade de desenvolvimento do modal ferroviário na microrregião de Toledo. Isso reforça o pressuposto que o desenvolvimento deste tipo de transporte poderá proporcionar maior eficiência no escoamento e recepção de materiais, maior eficiência energética, menor impacto ao meio ambiente, redução de gargalos urbanos de mobilidade, tendo em vista a menor circulação de caminhões e carretas nos entornos da região.

Apesar da força e da vocação regional em termos de produção, geração de emprego, renda e impostos, as condições de infraestrutura logística podem comprometer o crescimento e o consequentemente o desenvolvimento nos próximos anos.

Sendo assim, a realização deste estudo se justifica por debater sobre os aspectos de infraestrutura que podem gerar limitação para região caso não sejam atendidos, pois os principais produtos produzidos e transformados na microrregião têm seu destino ao mercado internacional e pela sua característica são sensíveis ao preço do frete, por serem de baixo valor agregado e de grande volume. Além disso, promover desenvolvimento regional pelo estudo que trata de melhoria do transporte de produtos com forte relação de quantidade transportada versus distância percorrida e sensibilidade ao valor de frete, cujo transporte ferroviário é mais adequado, e ainda, pela capacidade do estudo em proporcionar o uso eficiente de recursos que favorecem o meio ambiente, podendo gerar novos investimentos, renda e tributo para a região.

Este estudo também justifica-se a medida que colabora com o desenvolvimento de material acadêmico na área de logística e transporte de cargas, podendo abrir caminhos para análises mais amplas que poderão corroborar para o avanço da microrregião.

\section{MATERIAIS E MÉTODOS}

Este trabalho classifica-se, quanto à sua natureza, como uma pesquisa aplicada, tendo o intuito de gerar conhecimentos a serem aplicados na prática. Desta forma, contempla fatores de interesses locais e regionais, corroborando para aplicação deste conhecimento pelas organizações e pelo poder público.

No tocante à abordagem, esta pesquisa possui um caráter qualitativo, pois, segundo Farias Filho e Arruda Filho (2012), parte de uma visão, na qual há uma relação dinâmica entre o pesquisador e o cotidiano vivido pela sociedade, entre o mundo objetivo e a subjetividade do observador, o que não pode ser traduzido em números. No que tange ao objetivo, este estudo tem natureza descritiva, pelo fato de analisar e descrever a demanda por frete ferroviário 
na microrregião de Toledo/PR. A pesquisa descritiva, comumente, analisa e interpreta dados no intuito de determinação dos efeitos resultantes no objeto de análise do trabalho.

Neste sentido, os dados podem ser classificados em primários e secundários. Inicialmente, neste trabalho, utilizou-se de dados secundários, por meio dos quais, apresentam-se as informações sobre a microrregião de Toledo/PR e sua dinâmica econômica, além de caracterizar as formas de escoamento da produção, expedição e recepção de produtos, principalmente, com destino ao mercado externo. Numa segunda etapa, foram levantados os dados primários, que conforme destaca Farias Filho e Arruda Filho (2012), são aqueles coletados em "primeira mão" pelo pesquisador, de forma que, anteriormente, não havia sido tratado por outro. De forma complementar, foi empregado nesta pesquisa a técnica de entrevista e observação. A tipologia utilizada foi a de entrevista não-estruturada, a qual contém perguntas abertas e menor grau de rigidez, tanto na sequência quanto no número de perguntas (LUDWIG, 2009). As entrevistas foram feitas frente a frente junto aos gestores estratégicos da área de logística e transportes das organizações que fizeram parte da pesquisa. O objetivo da realização das entrevistas foi a elucidação dos tipos de produtos transformados, o volume de produção, os meios de transportes utilizados para o escoamento da produção, bem como sua percepção quanto à operação e competitividade do setor. Neste sentido, o roteiro da entrevista foi: a) volume transformado; b) volume expedido; c) destinos da produção; d) meios de transportes utilizados; e) volume recebido; g) origem de produtos recebidos; h) percepção do respondente quanto aos modos de transporte, principalmente à ferrovia.
Também foi utilizada a técnica observação, que é entendida como um contato direto do pesquisador com o objeto pesquisado. É imprescindível que esta técnica seja planejada, estruturada e controlada. Em pesquisas qualitativas a técnica de observação torna-se um caminho fundamental, pois permite captar informações dos sujeitos ou objetos investigados, como seu modo de pensar, sentir, agir, seus valores entre outros (LUDWIG, 2009).

Quanto ao local e amostragem, os estudos foram concentrados na microrregião de Toledo, a qual juntamente com as microrregiões de Cascavel e Foz do Iguaçu compõem a mesorregião oeste do estado do Paraná e, a amostragem, se deu em quatro empresas de grande porte do ramo agropecuário, sendo que três dessas, operam com transformação de produtos de origem animal e expedem a produção em contêineres frigorificados, em sua maioria, para o mercado externo via porto de Paranaguá, aqui nesta pesquisa, denominadas de A, B e C. e, a quarta empresa, classificada como D, atua no recebimento e expedição de grãos, principalmente, soja.

Estas empresas também demandam uma série de produtos como: fertilizantes, corretivos agrícolas e combustíveis, estes, também no perfil de transporte do modo ferroviário. Foi também selecionada para entrevista uma empresa de médio/grande porte do ramo de distribuição de ferro e aço que está localizada na cidade de Toledo, a qual distribui para toda microrregião, e que nesta pesquisa, está denominada como empresa $\mathrm{E}$.

Além dessas empresas entrevistadas, foi entrevistado um engenheiro agrônomo da Empresa de Assistência Técnica e Extensão Rural (EMATER), responsável pelas lavouras da microrregião de Toledo, 
no intuito de levantar informações quanto ao consumo de fertilizantes e calcário na área estudada.

Ademais, foi realizada uma visita técnica guiada ao pátio de transbordo ferroviário da empresa Estrada de Ferro Paraná Oeste S/A - Ferroeste, responsável pelo transporte ferroviário de toda região oeste paranaense, com o objetivo de realizar uma observação dos processos e atividades na movimentação ferroviária. O gestor operacional da empresa, além de acompanhar na visita técnica, colaborou com informações acerca dos principais produtos transportados e respectivos volumes das cargas movimentadas, por meio de entrevista não estruturada.

\section{RESULTADOS E DISCUSSÃO}

A existência de uma infraestrutura adequada para o transporte de cargas, além de potencializar as atividades empresariais, pode proporcionar melhorias na qualidade de vida de uma região, ampliar a eficiência empresarial e, consequentemente, aumentar a rentabilidade ao prover um aumento da renda e disponibilidade de postos de trabalho (MARTINS e CAIXETA-FILHO, 2013),

Neste aspecto, este trabalho de pesquisa buscou identificar quais os principais produtos produzidos na microrregião de Toledo, que precisam ser expedidos para outras regiões do país e para o porto de Paranaguá/PR com destino à exportação, bem como, produtos que chegam à região, em grande quantidade, necessários para a dinamização da economia regional, considerando algumas características básicas como sensibilidade ao valor do frete e relação de quantidade transportada versus distância percorrida.
Os resultados da análise realizada apontam que dentre os produtos preconizados pela ANTT como favoráveis ao transporte ferroviário, praticamente todos, são movimentados na microrregião de Toledo, exceto carvão mineral, clinquer e minério de ferro.

$\mathrm{Na}$ sequência, apresenta-se os resultados da análise de cada tipo de produto estudado, considerando as características das cargas e traçando uma relação com o referencial teórico utilizado.

\section{SOJA}

Conforme dados do IBGE (2014), o Paraná produziu no ano de 2014 aproximadamente 15 milhões de toneladas de soja, sendo que $10 \%$ deste montante foi produzido pela microrregião de Toledo, o que demonstra o grande volume de produção, e consequentemente, de movimentação deste grão realizada na microrregião.

Dado a importância da soja para a economia da microrregião, bem como sua característica de ser uma commoditie, e desta forma ser sensível ao valor do frete, seria lógico seu transporte ser efetuado via modo ferroviário, uma vez que cumpre com o que preconiza tanto a ANTT quanto a ANTF referente aos quesitos: quantidade transportada, distância percorrida, pois, está acima de $600 \mathrm{~km}$ de distância do Porto de Paranaguá que é o principal destino de exportação.

Barat (2009), corrobora com tal afirmativa ao apontar que o Brasil, dado suas dimensões continentais, apresenta-se como grande produtor agropecuário, o que torna relevante que a movimentação, principalmente, deste tipo de carga, seja realizada por um modo de transporte que apresente maior eficiência, no sentido de reduzir o valor do frete e melhorar a competitividade da 
produção. O modo ferroviário é apontado pelo autor como o mais adequado devido suas características de deslocamento, eficiência energética e relação volume versus peso. Outros autores como Alvarenga e Novaes (2000) apontaram que o transporte ferroviário é eficiente quando operado a médias/longas distâncias, preferencialmente, em corredores especializados. Este apontamento está ligado à realidade que ocorre na microrregião estudada, que está localizada à aproximadamente $600 \mathrm{~km}$ do destino final da produção que é o porto de Paranaguá.

Neste contexto, somente a empresa D movimenta em torno de 300 mil toneladas de produtos na microrregião de Toledo. Deste montante, em torno de 100 mil toneladas são de soja, movimentadas em diversos postos de recebimento, e o excedente são de calcário, fertilizantes e defensivos. De acordo com os comentários do gerente, toda movimentação da empresa se dá por rodovia, pois a ferrovia, da maneira como se apresenta, não atende às necessidades da empresa, e ressalta ainda, que quando tentaram utilizar o referido modal, os custos aumentaram, além de perder agilidade da operação.

Sendo assim, realizou-se uma comparação entre o escoamento deste produto via modo rodoviário, mais utilizado atualmente, com o modo ferroviário, que seria o mais indicado para este tipo de produto. Cabe salientar que na safra de 2014 o Paraná exportou 6,6 milhões de toneladas de soja em grãos, o que correspondeu à $45 \%$ da produção total do Estado que foi de 14,8 milhões de toneladas, sendo assim, este mesmo (\%) foi aplicado para a microrregião de Toledo, a qual produziu 1,5 milhões de toneladas em 2014 e, consequentemente, deste montante foi estimado a exportação de aproximadamente $710 \mathrm{mil}$ toneladas.
Tabela 1. Comparativo de transportes no escoamento da soja da Microrregião de Toledo/PR em 2014.

\begin{tabular}{ccc}
\hline Quantidade & $\begin{array}{c}\text { Modo Rodoviário } \\
\text { bi-trem graneleiro } \\
\text { de 35t }\end{array}$ & $\begin{array}{c}\text { Modo Ferroviário } \\
\text { Vagão graneleiro } \\
\text { de 60 t }\end{array}$ \\
\hline 709.295 & 20.268 & 11.839 \\
\hline
\end{tabular}

Fonte: Elaboração dos autores com base em dados da pesquisa.

Conforme demonstrado na tabela 1, se o escoamento da soja fosse efetuado via modo ferroviário, seriam necessários aproximadamente doze mil vagões de trem, os quais transportariam o equivalente a mais de vinte mil carretas bi-trens.

Essa mudança no modo de transporte poderia proporcionar melhoria na competitividade do agronegócio da microrregião, pois o custo do frete seria menor, além de impactar menos o meio ambiente, diminuir os gargalos rodoviários ao entorno da microrregião, na área urbana e, ainda, reduzir a incidência de acidentes.

Este novo cenário, vem de encontro com as afirmações de Ballou (1993) e Fleury (2002), os quais apontam que o transporte e a armazenagem de cargas abrigam a maior parte dos custos logísticos, impactando diretamente no grau de competitividade de uma empresa ou de uma região.

Em entrevista ao gestor da empresa Ferroeste, este comentou que, muitas vezes, as empresas transportam a soja por rodovia, pois, há um contrato pronto que rege o prazo de entrega e retorno do caminhão com outro tipo de produto, como fertilizante, por exemplo, e que neste cenário a ferrovia não consegue atender. Outro fator a ser considerado, consiste na alta oferta de caminhões em determinadas épocas do ano, o que reduz o valor do frete rodoviário, colocando-o em um patamar próximo ao operado pela ferrovia, o que inviabiliza a operação. 


\section{CONTÊINERES FRIGORIFICADOS}

Diversas são as empresas do ramo agropecuário, que fazem parte da microrregião de Toledo, e que estão intimamente ligadas ao agronegócio. Diante disso, o conjunto de sistemas agroindustriais como soja, aves, suínos, peixe etc., apresentam grandes proporções de produção primária e de transformação, principalmente, de proteína de origem animal. Conforme a metodologia empregada para análise dessa pesquisa, foram selecionadas três empresas de grande porte que operam com transformação de produtos de origem animal, principalmente, na cadeia do frango de corte que expedem sua produção via contêineres frigorificados para diversas regiões no mercado interno, e também mercado externo via porto de Paranaguá. Nesta análise, as empresas que participaram da pesquisa através da técnica de entrevista não estruturada foram denominadas como empresa A, B e C.

Existem duas empresas, cuja principal produção está centrada no frango de corte. Este produto foi o responsável em 2015 por colocar o Paraná na liderança deste segmento no valor bruto de produção (VBP) nacional, consequentemente, a microrregião de Toledo classifica-se como maior produtora nesse setor e detêm o maior valor do VBP do Estado.

De acordo com os resultados obtidos durante a pesquisa, a empresa A apresentou um volume de produção de produtos de origem animal, os quais são frigorificados, de 306 mil toneladas anuais. Este valor mostra-se estagnado desde o ano de 2010 até o ano de 2015 e não há expectativa para aumento, pois, conforme relatado pelo gestor que participou da entrevista, a planta fabril localizada na microrregião de Toledo está totalmente comprometida com este volume de produção, e novos investimentos estão sendo feitos pela companhia em outras regiões do país, e também no exterior. O fator de eficiência no escoamento da produção, segundo o respondente, é preponderante na decisão de novos investimentos em plantas fabris da companhia. A dificuldade e o custo de escoamento dos produtos da planta em questão pesou na decisão por investimentos em outros locais, entre outros fatores.

Quando citado o fator eficiência no escoamento da produção, este é relacionado a falta ou disponibilidade de infraestrutura para o transporte de cargas. Um estudo da Confederação Nacional do Transporte - CNT (2013) destaca que a infraestrutura é pré-requisito para geração de eficiência em operações logísticas, apresentando-se como fator relevante para o progresso de empresas e regiões. Além disso, este estudo ressalta que os fatores chaves de infraestrutura são: transportes, telecomunicações, energia entre outros, sendo o fator transporte um dos mais importantes, pois trata de dinamizar a economia de uma região e potencializar os fatores de produção. Dalmás (2008) corrobora com tal afirmativa, ao salientar que a falta de infraestrutura pode comprometer a disponibilidade de produtos e, consequentemente, diminuir a competitividade das organizações e regiões.

Considerando a produção atual de 306 mil toneladas anuais, este montante equivale à movimentação de mais de 8 mil carretas bi-trem de 35 toneladas, que poderiam ser substituídas por vagões ferroviários, o que reduziria o fluxo de veículos ao entorno da microrregião e, consequentemente, causaria menor impacto ao meio ambiente, além de reduzir o valor do frete e tornar o produto e a empresa mais competitiva, gerando externalidades de crescimento e desenvolvimento, tanto para a 
organização como para a microrregião. Cabe salientar, que $100 \%$ da produção da empresa A é movimentada via modo rodoviário, pois, segundo o gestor entrevistado, o modo ferroviário como é operado na região não atende as necessidades das operações logísticas da empresa. Foi citado pelo respondente como entraves: falta de ramal - posto de transbordo na cidade de Toledo que é a sede da empresa, a burocracia, a demora de viagem (velocidade cruzeiro de $35 \mathrm{~km} / \mathrm{h}$ - de Cascavel à Paranaguá - 7 dias), isto devido também ao traçado que a ferrovia tem, o sucateamento da linha e políticas de operação entre as empresas consorciadas. Estes fatores, são reiterados à afirmativa de Barat (2009), que aponta os entraves ao uso mais efetivo do transporte ferroviário, os quais limitam a competitividade das organizações e regiões.

Outro fator relevante, é que a empresa A tem a comercialização de seu produto em torno de $80 \%$ no mercado interno e, apenas $20 \%$, direcionada para o mercado externo. Segundo o gestor entrevistado, o tempo de deslocamento neste caso é de fundamental importância para o sucesso da operação, pois ocorrem pressões sobre prazos e diminuição de estoques por parte de toda cadeia de suprimentos, sendo assim, o modo ferroviário na forma como se apresenta, atualmente, na região não consegue atender, dado suas limitações de velocidade, atendimento, armazenagem e transbordo.

Este cenário de falta de planejamento e investimentos no modo ferroviário é comentado por Branco (2007), que retrata o desequilíbrio da matriz de transportes brasileira e como isto compromete a competitividade dos transportes de carga e impacta diretamente nas organizações e regiões que dependem dessas operações.

A empresa B apresentou um volume de produção em torno de 240 mil toneladas em 2015. Deste montante movimentou 130 mil toneladas no que tange produtos frigorificados via contêiner.

Tabela 2. Volume e modo de transporte para escoamento da produção da empresa B.

\begin{tabular}{cccc}
\hline Anos & $\begin{array}{c}\text { Produção } \\
\text { frigorificados } \\
(1000 \mathrm{t})\end{array}$ & $\begin{array}{c}\text { Rodoviário } \\
\text { Container de } \\
26 \mathrm{t}\end{array}$ & $\begin{array}{c}\text { Ferroviário } \\
\text { Contêineres de } \\
26 \mathrm{t}\end{array}$ \\
\hline 2007 & 74.958 & 74.958 & não utilizava \\
2008 & 84.370 & 84.370 & não utilizava \\
2009 & 90.038 & 90.038 & não utilizava \\
2010 & 93.106 & 93.106 & não utilizava \\
2011 & 88.946 & 88.946 & não utilizava \\
2012 & 96.434 & 96.434 & não utilizava \\
2013 & 91.624 & 80.920 & 10.704 \\
2014 & 109.148 & 73.866 & 35.282 \\
2015 & 130.208 & 82.914 & 47.294 \\
\hline Fonte· Elaboração dos autores com base em dados da pesquisa.
\end{tabular}

Conforme se observa na tabela 2, tem ocorrido na empresa B uma expressiva evolução no seu volume de produção. Outro ponto importante a analisar é que desde o ano de 2012 começou a operar também com o modo ferroviário, no qual pode se observar um gradativo aumento no volume transportado por este modo até o ano de 2015. É possível perceber que no ano de 2013, primeiro ano de utilização do transporte ferroviário pela empresa $\mathrm{B}$, ela movimentou $11,5 \%$ do total de cargas frigorificadas pela ferrovia. Já no ano de 2014 houve um aumento para $32 \%$ e no ano de 2015 para $36,5 \%$.

Segundo o gestor entrevistado, este aumento se deu devido à um consórcio de empresas que operam no pátio de transbordo que fica na cidade de Cascavel e que por uma parceria atuam como um 
condomínio logístico, desta forma, conseguiram reduzir custos e melhorar entraves na operação. No momento da entrevista, o gestor da empresa B argumentou que o desenvolvimento do modo ferroviário para atendimento a microrregião é de suma importância, dado as características de produtos e quantidades movimentadas. Além disso, salientou que mesmo havendo crescimento na movimentação de cargas via ferrovia, nos últimos anos, os valores devem permanecer estagnados devido alguns fatores, tais como problemas operacionais apresentados por três operadoras que realizam este trecho de Cascavel à Paranaguá; inexistência de oferta constante de vagões; excesso de reclamações, pertinentes, acerca de vagões com limitação de acesso à energia durante o período de viagem, o que ocasiona danos aos produtos frigorificados, além de não haver ramal mais próximo para o transbordo.

No que tange às perspectivas de crescimento, a empresa $\mathrm{B}$, diferentemente da $\mathrm{A}$, relata que em seu planejamento de crescimento e expansão, as cargas frigorificadas movimentadas via contêiner irão crescer significativamente.

Tabela 3. Perspectiva de crescimento em volume de produção para a empresa B.

\begin{tabular}{cc}
\hline Ano & Produção (1000 t) \\
\hline 2016 & 150.800 \\
2017 & 176.800 \\
2018 & 197.600 \\
2019 & 208.000
\end{tabular}

Fonte: Elaboração dos autores com base em dados da pesquisa.

Conforme apontado na tabela 3, é possível identificar o crescimento em volume de produção e movimentação previsto pela empresa $\mathrm{B}$ para os próximos anos. Além disso, o gestor da empresa ressalta que no planejamento de expansão da mesma, consta o início de operações no ramo da piscicultura, e que em razão disto, no prazo de 3 anos, ocorrerá um grande incremento na demanda por contêineres frigorificados. A previsão inicial, considera um volume de produção em torno de 1.000 toneladas/mês, podendo chegar a 6.000 toneladas/mês dependendo da adaptação e investimento do corpo integrado de produtores. O gestor salientou, exatamente, o que preconiza as agências ANTT e ANTF, de que o modo ferroviário é o melhor meio de escoar a produção de frigorificados via contêiner, pois o produto tem grande sensibilidade ao valor de frete, e acaba perdendo competitividade internacional devido aos custos logísticos de transporte e armazenagem. Além disso, destacou a precariedade do trecho Cascavel à Paranaguá, acrescentando ainda, outros entraves no tocante a armazenagem, desorganização na chegada e transbordo no porto de Paranaguá.

Já a empresa C, apresentou em 2015 uma produção de 84 mil toneladas. Conforme observa-se na tabela 4, esta empresa apresentou uma evolução em sua quantidade transformada de produtos frigorificados, e segundo informações prestadas pelo gestor, referente ao ano de 2015, do total produzido, $50 \%$ foi destinado ao mercado interno e, totalmente, transportado por rodovia, sendo que os outros $50 \%$ teve como destino o mercado externo. Das $42 \mathrm{mil}$ toneladas destinadas ao mercado externo, $45 \%$ foram escoadas via ferrovia e $55 \%$ via rodovia.

Tabela 4. Volume de produção de frigorificados da empresa C.

\begin{tabular}{cc}
\hline Ano & Produção (1000 t) \\
\hline 2010 & 72.379 \\
2011 & 78.404 \\
2012 & 79.253 \\
2013 & 82.760 \\
2014 & 84.377 \\
2015 & 83.914 \\
\hline
\end{tabular}

Fonte: Elaboração dos autores com base em dados da pesquisa. 
A empresa $\mathrm{C}$, participa do consórcio de empresas que transportam contêineres frigorificados e que operam no pátio de transbordo da Ferroeste em Cascavel. Segundo o gestor, quando iniciaram as operações obteve-se ganhos com relação a operação e custo, porém, ainda assim transporta maior parte pela rodovia devido aos mesmos entraves citados pelas demais empresas: baixa oferta de vagões; impossibilidade de acesso contínuo à energia elétrica no decorrer de todo percurso; dificuldades de agendamento e alto índice de burocracia.

O gestor aponta ainda, que é de fundamental importância tanto o desenvolvimento de ramais e pátios que atendam a ferrovia na microrregião de Toledo, como também a melhora no atendimento que a Ferroeste já presta, principalmente, no que tange o planejamento e gestão das operações. Segundo ele, a falta de uma ferrovia eficiente gera prejuízos e diminui a competitividade da indústria local.

As empresas B e C comercializam grande parte de sua produção no mercado internacional, sendo assim, os gestores apontaram que a sustentabilidade dos negócios está diretamente relacionada a redução de custos de operação, principalmente os logísticos. Esta afirmativa vem de encontro com o que Ballou (1993) e Fleury (2002) apontaram a respeito dos custos de operações logísticas, em que o transporte e a armazenagem congregam a maior carga dos custos logísticos e que impactam diretamente no grau de competitividade de uma empresa ou região.

Neste aspecto, Coeli (2004) argumenta que a gestão, tanto de empresas como do poder público, deve estar atenta às operações logísticas, pois estas, apresentam tal importância para os negócios, que englobam cerca de $7 \%$ a $10 \%$ dos custos de operação. Ainda segundo a autora, o transporte representa $60 \%$ do total destes custos, residindo aí uma grande oportunidade de gerar vantagem competitiva frente a outros mercados e definir estratégias de transportes mais eficientes que poderão colocar a empresa ou país em melhor posicionamento num mercado cada vez mais competitivo.

E é neste contexto que se insere a microrregião de Toledo, em um cenário de grande incerteza, principalmente, na visão da empresa $\mathrm{B}$, pois, conforme já apontado neste estudo, em torno de $80 \%$ de sua produção tem destino ao mercado externo, e é de suma importância que a empresa possa garantir sua competitividade e sustentabilidade.

Uma oportunidade neste aspecto, consiste na possibilidade de redução dos custos por meio das operações de transportes, no que tange ao escoamento da produção, pois, ao considerar as três empresas, aqui denominadas como A, B e C, é possível verificar que em conjunto, elas movimentam em torno de 520 mil toneladas anuais, da microrregião de Toledo para outras regiões e para o mercado externo.

De acordo com esse estudo, embasado na literatura de logística e transporte de cargas, bem como nos documentos das agências ANTT e ANTF, seria lógico que este montante de produção fosse movimentado via modo ferroviário, pois, atende às características de grande volume de movimentação, distância percorrida e sensibilidade ao valor do frete, corroborando assim, com as afirmações de Barat (2009), Ballou (1993), Fleury (2002), Martins e Caixeta-Filho (2013), entre outros autores que trataram sobre o transporte de cargas, relacionando suas características e potencialidades.

Neste aspecto, o desenvolvimento do modo ferroviário proporcionaria melhor competitividade, tanto para as organizações como para a microrregião como um todo, além de outros benefícios como 
diminuição de gargalos nas rodovias e nas vias urbanas, menor impacto ao meio ambiente entre outros fatores positivos à sociedade.

Cabe salientar que além destas três empresas entrevistadas, a microrregião de Toledo abriga outras empresas do segmento de produtos frigorificados, embora com menor expressão em volume de produção, mas que poderiam também utilizar, se desenvolvido, o modo ferroviário para escoamento de sua produção, bem como recepcionar os insumos que fazem parte de suas operações de produção.

Ademais, na cidade de Assis Chateaubriand, que faz parte da microrregião de Toledo, está em curso no decorrer de 2016 relevantes investimentos em um novo frigorífico de suínos, o qual prevê abate diário inicial em torno de quinze mil animais a partir de 2018. Este novo empreendimento agroindustrial atenderá tanto mercado interno quanto externo, e certamente demandará transporte ferroviário devido suas características de quantidade transportada, distância percorrida e sensibilidade ao valor de frete.

Sendo assim, após esta abordagem e análises quanto aos contêineres frigorificados, na próxima secção será abordado o produto cimento.

\section{CIMENTO}

Segundo dados do Sindicato da Indústria do Cimento - SNIC (2013), existe um fator para calcular o consumo de cimento por município no Brasil, que é a quantidade per capita. Na tabela 5, apresenta-se o consumo aparente de cimento para a microrregião de Toledo no ano de 2013, baseado nesta metodologia, com o intuito de analisar o volume de movimentação deste produto que chega até a microrregião para dar suporte ao avanço do setor da construção civil.
Tabela 5. Consumo aparente de cimento na microrregião de Toledo no ano de 2013.

\begin{tabular}{clcc}
\hline Municípios & $\begin{array}{c}\text { Habitantes } \\
(\mathbf{2 0 1 0})\end{array}$ & $\begin{array}{c}\text { 353 Kg } \\
\text { /hab./ano* }\end{array}$ \\
\hline 1 & A. Chateaubriand & 33.025 & 11.657 .825 \\
2 & Diamante d’Oeste & 5.027 & 1.774 .531 \\
3 & Entre Rios do Oeste & 3.926 & 1.385 .878 \\
4 & Formosa do Oeste & 7.541 & 2.661 .973 \\
5 & Guaíra & 30.704 & 10.838 .512 \\
6 & Iracema do Oeste & 2.578 & 910.034 \\
7 & Jesuítas & 9.001 & 3.177 .353 \\
8 & Mal. C. Rondon & 46.819 & 16.527 .107 \\
9 & Maripá & 5.684 & 2.006 .452 \\
10 & Mercedes & 5.046 & 1.781 .238 \\
11 & Nova Santa Rosa & 7.626 & 2.691 .978 \\
12 & Ouro Verde Oeste & 5.692 & 2.009 .276 \\
13 & Palotina & 28.683 & 10.125 .099 \\
14 & Pato Bragado & 4.822 & 1.702 .166 \\
15 & Quatro Pontes & 3.803 & 1.342 .459 \\
16 & Santa Helena & 23.413 & 8.264 .789 \\
17 & São J. das Palmeiras & 3.830 & 1.351 .990 \\
18 & São Pedro Iguaçú & 6.491 & 2.291 .323 \\
19 & Terra Roxa & 16.759 & 5.915 .927 \\
20 & Toledo & 119.313 & 42.117 .489 \\
21 & Tupãssi & 7.997 & 2.822 .941 \\
\hline & & $\mathbf{3 7 7 . 7 8 0}$ & $\mathbf{1 3 3 . 3 5 6 . 3 4 0}$ \\
& & &
\end{tabular}

Fonte: Adaptada de Sindicato Nacional das Indústrias de Cimento (2013).

Cabe salientar que o cimento destinado à microrregião de Toledo é oriunda da região metropolitana de Curitiba/PR ou do Estado de São Paulo, em razão disto, apresenta a relação de distância percorrida favorável ao transporte ferroviário.

Observa-se que o consumo de cimento demandado na microrregião de Toledo ultrapassa as 133 mil toneladas e, desta forma, atende aos requisitos de grande volume de movimentação, distância percorrida, pois, ultrapassa os $500 \mathrm{~km}$ de distância e, ainda, sensibilidade ao valor do frete, demonstrando que há demanda de transporte ferroviário para este tipo de produto.

No que tange o progresso econômico da microrregião de Toledo, o avanço da construção civil apresenta-se como indicador favorável. Ademais, se melhorar a competitividade de preço em seu insumo principal, que neste caso é o cimento, causará 
externalidades positivas para toda cadeia de industrialização, comercialização, bem como para a população em geral.

Cabe destacar uma observação importante, que se houvesse um sistema ferroviário eficiente ocorreria um fluxo de soja e produtos da microrregião de Toledo, e ao descarregarem em Paranaguá, poderiam voltar com a carga de cimento nos vagões, gerando uma otimização na logística de transporte via ferroviária.

Feito esta análise, a próxima seção apresenta as considerações sobre fertilizantes e calcário.

\section{FERTILIZANTES E CALCÁRIO}

Em uma região, onde a principal dinâmica econômica está centrada no agronegócio, fica evidente que diversos tipos de produtos relacionados a esta atividade sejam demandados em grandes quantidades, desta forma, fertilizantes e calcário são exemplos destes tipos de produtos.

Conforme apontado pela ANTT, estes produtos geralmente são transportados em grande quantidade e também apresentam sensibilidade ao preço de frete, o que corrobora para a afirmativa de que, se uma região demanda uma quantidade considerável desse tipo de produto, o modo de transporte mais adequado é o ferroviário, dado suas características já mencionadas nesta pesquisa.

Para se chegar a um valor estimado de consumo na área estudada, foi realizada uma entrevista não estruturada com um representante da Empresa de Assistência Técnica e Extensão Rural EMATER de Toledo/PR, tendo como participante, o engenheiro agrônomo responsável por assistência às lavouras na microrregião. $O$ respondente informou que a média de consumo de fertilizantes nesta localidade é de $275 \mathrm{~kg} / \mathrm{ha}$, e que para o calcário a média de consumo é de $2.000 \mathrm{~kg} / \mathrm{ha}$. Após o levantamento dessas informações, foi possível chegar a um valor estimado cruzando com os dados de área plantada da microrregião.

Devido à vocação agropecuária da área estudada, estes produtos são utilizados em larga escala, conforme se observa na tabela 6, a qual aponta o consumo de fertilizantes e calcário no conjunto dos 21 municípios de análise para o ano de 2014.

Tabela 6. Consumo aparente de fertilizantes e calcário na Microrregião de Toledo em 2014.

\begin{tabular}{|c|c|c|c|c|}
\hline & Municípios & Área Plantada (ha) & Fertilizantes (275 kg/ha) & Calcário (2000 kg/ha) \\
\hline 1 & Assis Chateaubriand & 84.438 & 23.220 .450 & 168.876 .000 \\
\hline 2 & Diamante d'Oeste & 24.278 & 6.676 .450 & 48.556 .000 \\
\hline 3 & Entre Rios do Oeste & 7.125 & 1.959 .375 & 14.250 .000 \\
\hline 4 & Formosa do Oeste & 25.048 & 6.888 .200 & 50.096 .000 \\
\hline 5 & Guaíra & 35.565 & 9.780 .375 & 71.130 .000 \\
\hline 6 & Iracema do Oeste & 7.968 & 2.191 .200 & 15.936 .000 \\
\hline 7 & Jesuítas & 29.565 & 8.130 .375 & 59.130 .000 \\
\hline 8 & Marechal Cândido Rondon & 54.038 & 14.860 .450 & 108.076 .000 \\
\hline 9 & Maripá & 21.562 & 5.929 .550 & 43.124 .000 \\
\hline 10 & Mercedes & 15.614 & 4.293 .850 & 31.228 .000 \\
\hline 11 & Nova Santa Rosa & 13.065 & 3.592 .875 & 26.130 .000 \\
\hline 12 & Ouro Verde do Oeste & 28.899 & 7.947 .225 & 57.798 .000 \\
\hline 13 & Palotina & 59.385 & 16.330 .875 & 118.770 .000 \\
\hline 14 & Pato Bragado & 7.521 & 2.068 .275 & 15.042 .000 \\
\hline 15 & Quatro Pontes & 10.039 & 2.760 .725 & 20.078 .000 \\
\hline 16 & Santa Helena & 41.076 & 11.295 .900 & 82.152 .000 \\
\hline
\end{tabular}




\begin{tabular}{|c|c|c|c|c|}
\hline 17 & São José das Palmeiras & 18.686 & 5.138 .650 & 37.372 .000 \\
\hline 18 & São Pedro do Iguaçú & 25.379 & 6.979 .225 & 50.758 .000 \\
\hline 19 & Terra Roxa & 76.916 & 21.151.900 & 153.832 .000 \\
\hline 20 & Toledo & 102.087 & 28.073 .925 & 204.174 .000 \\
\hline 21 & Tupãssi & 26.366 & 7.250 .650 & 52.732 .000 \\
\hline & & 714.620 & 196.520.500 & 1.429 .240 .000 \\
\hline
\end{tabular}

Fonte: Adaptada de entrevista realizada com Engenheiro Agrônomo da EMATER Toledo/PR (2016).

Diante as observações extraídas a partir da tabela 6, fica evidente o grande volume de utilização desses dois tipos de produtos, sendo assim, seria interessante para a microrregião que estes produtos chegassem com preço mais competitivo para consumo, isto reduziria os custos de produção e consequentemente melhoraria a competitividade do produto final e, ainda, daria suporte para custos mais competitivos para os produtos seguintes da cadeia de suprimentos.

\section{COMBUSTÍVEL}

$\begin{array}{rrrrr}\text { Mediante } & \text { o } & \text { expressivo } & \text { crescimento } & \text { e } \\ \text { desenvolvimento } & \text { da } & \text { microrregião } & \text { de Toledo, } & \text { o }\end{array}$

Tabela 7. Consumo de combustíveis na microrregião de Toledo de 2011 a 2013 em milhares de litros.

\begin{tabular}{lrrrr}
\hline LOCALIDADE & DIESEL & ETANOL & GASOLINA & TOTAL \\
\hline Assis Chateaubriand & 23.027 & 24.438 & 24.156 & 71.621 \\
Diamante d'Oeste & 698 & 448 & 843 & 1.989 \\
Entre Rios do Oeste & 3.177 & 3.292 & 3.807 & 10.275 \\
Formosa do Oeste & 3.137 & 3.546 & 3.773 & 10.456 \\
Guaíra & 50.930 & 63.869 & 75.996 & 190.795 \\
Iracema do Oeste & 845 & 871 & 814 & 2.530 \\
Jesuítas & 4.899 & 5.250 & 5.368 & 15.517 \\
Marechal Cândido Rondon & 48.987 & 51.929 & 52.459 & 153.375 \\
Maripá & 2.302 & 2.475 & 2.550 & 7.327 \\
Mercedes & 2.385 & 2.456 & 3.818 & 8.659 \\
Nova Santa Rosa & 4.330 & 4.318 & 4.354 & 13.002 \\
Ouro Verde do Oeste & 2.341 & 2.489 & 2.649 & 7.479 \\
Palotina & 23.498 & 26.125 & 27.855 & 77.478 \\
Pato Bragado & 2.097 & 2.784 & 2.697 & 7.578 \\
Quatro Pontes & 1.479 & 1.571 & 1.750 & 4.799 \\
Santa Helena & 12.613 & 14.943 & 14.475 & 42.031 \\
São José das Palmeiras & 674 & 323 & 816 & 1.813 \\
São Pedro do Iguaçú & 1.533 & 1.959 & 1.737 & 5.228 \\
Terra Roxa & 33.853 & 39.647 & 41.507 & 115.006 \\
Toledo & 96.466 & 104.170 & 109.776 & 310.411 \\
Tupãssi & 6.357 & 7.001 & 6.922 & 20.279 \\
\hline TOTAL & $\mathbf{3 2 5 . 6 2 6}$ & $\mathbf{3 6 3 . 9 0 1}$ & $\mathbf{3 8 8 . 1 1 9}$ & $\mathbf{1 . 0 7 7 . 6 4 7}$ \\
\hline Font & & & &
\end{tabular}

Fonte: Adaptado de ANP (2015) produto combustível apresenta consumo relevante. Conforme já mencionado, a dinâmica econômica da área estudada centra-se no agronegócio, desta forma, além de demandar grande quantidade para consumo urbano, demanda também, consumo notório na área rural, principalmente, de óleo diesel para as máquinas agrícolas e caminhões.

Para uma melhor análise de tal demanda, na tabela 7 apresenta-se o consumo de combustíveis na microrregião de Toledo conforme dados extraídos da Agencia Nacional de Petróleo (ANP, 2015). 
Conforme demonstrado na tabela 7, o consumo de combustível ultrapassou 1 bilhão de litros entre o ano de 2011 e 2013. Para se ter uma ideia, somente no ano de 2013 a movimentação ultrapassou 388 milhões de litros entre os três tipos (diesel, etanol e gasolina), o que demonstra um volume expressivo de movimentação deste tipo de produto.

O combustível que chega a microrregião de Toledo procede de distribuidoras localizadas, em sua maioria, na região metropolitana de Curitiba/PR.

Conforme apontado pela ANTT, o produto combustível devido suas características de ser a granel, e também por ser sensível ao preço de frete, para ser mais competitivo deveria ser transportado via modo ferroviário quando observado as relações de quantidade transportada e distância percorrida. Estes dois fatores, quantidade transportada e distância, apresentam demanda por frete ferroviário na microrregião de Toledo, devido ao expressivo consumo, como também encontra-se acima de $500 \mathrm{~km}$ de distância da região de origem do produto, desta forma, considera-se que o modo ferroviário possibilita gerar maior eficiência e preços mais favoráveis no custo do frete.

Para traçar um comparativo em relação ao modo rodoviário, que atualmente é o mais utilizado para este tipo de carga na microrregião, a tabela 8 demonstra as diferenças entre os dois modos.

Tabela 8. Comparativo entre modais de transporte de combustível na microrregião de Toledo/PR em 2014.

\begin{tabular}{ccc}
\hline Quantidade & $\begin{array}{c}\text { Modo Rodoviário } \\
\text { bi-trem de 47.000 } \\
\text { litros }\end{array}$ & $\begin{array}{c}\text { Modo Ferroviário } \\
\text { Vagão tanque de } \\
\mathbf{1 1 8 . 0 0 0} \text { litros }\end{array}$ \\
\hline 388 milhões & 8.256 & 3.289
\end{tabular}

Fonte: Elaboração dos autores com base em dados da pesquisa.
O comparativo apresentado na tabela 8 aponta que se a quantidade demandada de combustíveis pela microrregião de Toledo fosse completamente transportada via modo ferroviário, pouco mais de três mil vagões substituiriam, aproximadamente, os oito mil bi-trens que deslocamse pelas rodovias. Cabe salientar que este tipo de produto tem muitas exigências legais dado sua periculosidade, e esta alteração no modo de transporte, iria colaborar para melhor segurança de terceiros no deslocamento da origem até o destino na microrregião, além disso, causaria menor impacto ao meio ambiente por ter maior eficiência energética e diminuiria o gargalo nas rodovias e entornos urbanos, inclusive melhorando o consumo de combustíveis de terceiros, haja vista que o fluxo de veículos ocorreria de forma mais ordenada, constante e com menos incidência de acidentes (FERROLEASE, 2016).

Feito esta análise acerca dos combustíveis, a próxima seção discute os resultados obtidos em relação aos produtos ferro e aço.

\section{FERRO E AÇO}

Devido ao avanço da economia, principalmente, no que tange o ramo da construção civil, os produtos ferro e aço tiveram significativo aumento em sua demanda. $\mathrm{Na}$ área estudada, encontra-se uma empresa distribuidora de ferro e aço que abastece toda microrregião de Toledo e parte da região oeste paranaense. Nesta pesquisa, a referida empresa recebe a denominação de empresa E.

Mediante entrevista realizada com o gestor de administração e materiais da empresa E, o mesmo destacou que não poderia fornecer maiores detalhes acerca do volume de movimentação, entretanto, 
informou que a empresa fornece pelo menos $80 \%$ do ferro e aço consumido no conjunto dos 21 municípios estudados. Além disso, salientou que detêm representação exclusiva para a região, de empresas de expressão nacional como a Gerdal S/A. Quando questionado sobre o sistema de recebimento $\mathrm{e}$ transporte, principalmente, quanto às possibilidades de movimentação destas cargas via modo ferroviário, o mesmo foi taxativo ao argumentar que não seria viável transportar ferro e aço por ferrovia. Explicou isso, ao afirmar que tais produtos são provenientes da região metropolitana de Curitiba e, pelo fato do tempo ser considerado um fator determinante, e que o trajeto via ferrovia neste percurso demora sete dias, seria necessário um aumento expressivo nos estoques, elevando ainda mais os custos, além disso, ressalta que não se têm segurança de entrega, entre outros entraves citados, como a burocracia e a desorganização deste modo na região.

Este cenário, comentado pelo gestor que participou da entrevista, foi confirmado com a visita ao pátio de transbordo da Ferroeste. Foi evidenciado por esta pesquisa o elevado grau de burocracia e processos demorados no que tange a utilização do modo ferroviário.

Todas as cargas para estes tipos de produtos são efetuados via modo rodoviário, dada a característica de flexibilidade e rapidez na entrega segundo o respondente. $\mathrm{O}$ mesmo concorda que o modo ferroviário melhoraria a competitividade do setor, bem como, traria outros benefícios para a sociedade, como a redução de gargalos nas rodovias e menor impacto ao meio ambiente, porém, salientou que só com muito investimento em tecnologia e gestão é que a ferrovia poderia atender a distribuição de ferro e aço para o interior do Estado.
Todo este conjunto de produção, analisado na microrregião de Toledo, além de outros setores influenciados pelo agronegócio como o da construção civil, atendem ao estudo feito por Reis (2007) quando afirmou que para o desenvolvimento da ferrovia em uma região é preciso de escala, ou seja, demanda para que os custos possam ser diluídos e possa ter aumento de lucros.

Após estas análises e discussões feitas com base nos produtos movimentados na microrregião de Toledo e as características do modo ferroviário conforme apontado pela ANTT, será apresentado as considerações finais deste trabalho de pesquisa.

\section{CONSIDERAÇÕES FINAIS}

Neste trabalho, foram levantados e analisados os produtos que demandam transporte ferroviário na microrregião de Toledo/PR. O estudo partiu da literatura sobre logística e transporte de cargas, bem como de documentos da ANTT, os quais apontam os produtos que tem características de ser transportados via modo ferroviário dado sua relação de distância percorrida versus quantidade transportada, bem como a sensibilidade ao valor do frete. $\mathrm{O}$ intuito foi de investigar tais produtos, e se estes demandam transporte ferroviário na microrregião de Toledo/PR.

Existe uma preocupação com a manutenção do crescimento e desenvolvimento econômico na microrregião a médio e longo prazo, neste sentido, este estudo buscou colaborar com informações sobre a demanda por transporte de cargas via modo ferroviário que apresenta-se mais eficiente para os tipos de cargas principais movimentadas na microrregião.

Sendo assim, as movimentações de carga que mais demandam estão relacionadas às commodities $\mathrm{e}$ 
produtos de economia de escala, que precisam de preços mais atrativos tanto de produção, quanto logísticos - transporte e armazenagem.

Fica evidente que o desenvolvimento do modo ferroviário, se analisado sob o prisma da demanda de cargas que a microrregião apresenta, torna-se importante, e poderá oferecer maior competitividade aos produtos que dinamizam a economia, promovendo desenvolvimento regional e causando externalidades positivas para toda sociedade.

Este estudo teve algumas limitações no que tange ao levantamento de dados de alguns produtos como: cimento, cal, fertilizantes e adubos. No caso do cimento, a estimativa foi feita com base no que diz um dado do sindicado nacional das indústrias cimenteiras referente ao consumo per capita desse tipo de produto. Já no caso da cal, não foram encontrados dados confiáveis, apenas para o calcário, que juntamente com o fertilizante foi feita uma estimativa mediante informações repassadas pela EMATER quanto ao consumo por hectare de área plantada na área estudada.

A pesquisa demostrou que a microrregião apresenta relevante demanda por transporte ferroviário, dado sua dinâmica econômica e característica voltada ao agronegócio. Neste sentido, por mais que não exista ramal ferroviário para atender a demanda por transporte ferroviário da microrregião de Toledo, existe um pátio de transbordo ferroviário no município de Cascavel que liga ao município de Guarapuava e, consequentemente, ao porto de Paranaguá, que poderia realizar as operações de escoamento e recepção de materiais, porém, o que se constatou foi que há diversos entraves nesta operação, fazendo com que torne-se ineficiente e que diversas empresas optem pelo modo rodoviário, mesmo este apresente, teoricamente, maiores custos, cause maior impacto ao meio ambiente e aumente os gargalos nas rodovias e entornos da região. Apresenta-se na ferrovia existente falta de gestão e planejamento para que a operação seja mais eficiente e possa proporcionar custo competitivo para as empresas e produtores que desejarem transportar por ferrovia.

Quanto aos entraves observados foi constatado que há falta de padronização no processo de agendamento de embarque, movimentação interna ineficiente no pátio ferroviário, falta de oferta constante de vagões, burocracia documental, utilização da estrutura para operações de cargas rodoviárias em detrimento às ferroviárias, entre outros.

É preciso que seja desenvolvido um planejamento concreto de melhoria de fluxo no pátio de transbordo, bem como que seja feito investimentos no melhoramento da linha no que tange vagões, locomotivas e aumento da bitola de $1 \mathrm{~m}$ para 1,6 m, além de adequações e ajustes no traçado, assim melhoraria a rodagem e aumentaria a velocidade de transporte. Estas ações aprimorariam a eficiência do trecho, o que poderia fazer com que as empresas embarcassem mais via ferrovia.

A microrregião de Toledo por se destacar no ramo do agronegócio nacional potencializa outras áreas da economia como construção civil, educação, comércio entre outras. É preciso investimentos que mantenham este crescimento e desenvolvimento a médio e longo prazo. O desenvolvimento do modo ferroviário para escoamento da produção regional, bem como a movimentação de produtos que precisam chegar até a microrregião é uma ação que dará sustentação ao evidente avanço desta economia. Ações de melhoria em gestão e planejamento da ferrovia que já existe (Ferroeste) poderá a curto prazo oportunizar custos e operações mais atrativos. 
Ademais, para a concretização e melhor análise de investimentos nessa área se faz necessários estudos futuros no que tange a viabilidade econômicofinanceira, e de engenharia para o desenvolvimento do modo ferroviário na microrregião.

Esta pesquisa apresentou que há demanda por transporte de cargas via ferrovia, assim, abre caminho para estudos mais aprofundados que apresentem as melhores opções sobre essa categoria de modal, bem como, a necessidade de implementar na microrregião de Toledo, uma infraestrutura adequada para complementar os modais de transporte da região.

Estudos futuros são necessários para analisar a implementação de novos pátios de transbordo ferroviário na região oeste do Paraná, englobando não só microrregião de Toledo, mas também, de Cascavel e Foz do Iguaçu. Ademais, ampliar o número de empresas analisadas na região oeste passa ser interessante.

Outra oportunidade que este estudo apresenta é a análise do trecho que ligará as cidades de Maracaju-MS à Lapa-PR, previsto no Programa de Investimentos em Logística etapa II e que passará pela microrregião de Toledo, avaliando as possibilidades de alocação de pátio de transbordo ferroviário dentro da microrregião e planejando uma melhor forma de organização e operação de transbordo.

Todos os autores declararam não haver qualquer potencial conflito de interesses referente a este artigo.

\section{REFERÊNCIAS}

ALVARENGA, A. C; NOVAES A. G. Logística Aplicada: Suprimentos e Distribuição Física. 3. ed. São Paulo: Blucher, 2000.

ANP. Vendas anuais de Etanol Hidratado e Derivados de Petróleo por Município. 2015. Disponível <http://www.anp.gov.br/?pg=79093\&m=\&t1=\&t2=\&t $3=\& \mathrm{t} 4=\& \mathrm{ar}=\& \mathrm{ps}=\& 1468597912135>$. Acesso em: 20 ago. 2015.

ANTF. O papel decisivo das ferrovias. In: As ferrovias e o futuro do país. 2014. Disponível em: $\langle$ http://www.antf.org.br/pdfs/presidenciaveis.pdf $>$.

Acesso em: fev. 2016.

ANTT. Transporte ferroviário. TRIC - Transporte Rodoviário Internacional de Cargas. 2013. Disponível em:

<http://appweb2.antt.gov.br/carga/ferroviario/ferrovia rio.asp >. Acesso em 17 maio. 2016.

BALLOU, R.H. Logística Empresarial. 1. ed. São Paulo: Atlas, 1993.

BARAT, J. Transporte ferroviário de carga no Brasil. Ano 07. ed. 55. 2009.

BRANCO, J. E. H. Estimativa da demanda de carga captável pela Estrada de Ferro Norte-Sul. Dissertação de Mestrado. 159 f. Universidade de São Paulo. Piracicaba, 2007.

CAIXETA FILHO, J. V. Gestão Logística do Transporte de Cargas. 11. ed. São Paulo, 2001.

CNT. Confederação Nacional do Transporte. Matriz do transporte de cargas no Brasil. Disponível em: <https://www.google.com.br/search?q=matriz+de+tra nsporte+de+cargas + no+brasil $+2014 \&$ espv $=2 \&$ biw $=1$ $366 \&$ bih $=638 \&$ source $=1$ nms $\&$ tbm $=i$ sch $\&$ sa $=X \&$ ved $=$ 0ahUKEwijqcL96I_QAhUFk5AKHQdWAlcQ_AUIB

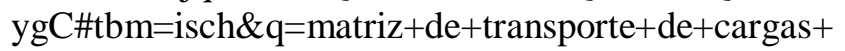
no+brasil $+2014+$ cnt\&imgrc $=1 \mathrm{sQBOu} I S w 52 \mathrm{eM} \% 3 \mathrm{~A}$ >. Acesso: maio. 2016.

COELI, C. C. de M. Análise da demanda por transporte ferroviário: o caso do transporte de grãos e farelo de soja na Ferronorte. Tese de Mestrado (Administração) - Instituto COPPEAD de Administração. Universidade Federal do Rio de Janeiro (UFRJ). Rio de Janeiro, 2004.

DALMÁS, S. R. da S. P. A logística de transporte agrícola multimodal da região Oeste do Paraná. Dissertação de Mestrado. 115 f. Universidade Federal do Oeste do Paraná - UNIOESTE. Toledo, 2008.

DERAL. Análise do VBPA - Valor Bruto da Produção Agrícola. Disponível em: <http://www.agricultura.pr.gov.br/arquivos/File/deral/ analise_12_01.pdf>. Acesso em: 05 jul. 2016. 
EMBRAPA. Soja em números (safra 2014/2015). $2014 . \quad$ Disponível em:

<https://www.embrapa.br/soja/cultivos/soja1/dadoseconomicos>. Acesso em: 13 fev. 2016.

FARIAS FILHO, M. C.; ARRUDA FILHO, E. J. M. Planejamento da Pesquisa Científica. 1. ed. São Paulo: Atlas, 2012.

FERROLEASE SÃO PAULO. Vagão Tanque. 2016. Disponível em: <http://www.ferrolease.com.br/frotavagao-tanque.html>. Acesso em: 05 jul. 2016.

FLEURY, P. F. Gestão estratégica do transporte. 2002.

IBGE. Produção agrícola municipal. 2014. Disponível em: <http://www.ibge.gov.br/home/estatistica/economia/p am/2014/default_xls.shtm>. Acesso em: 13 fev. 2016.

LUDWIG, A. C. W. Fundamentos e prática de metodologia científica. 1. ed. São Paulo: Vozes, 2009.

MARTINS, R. S.; CAIXETA FILHO, J. V. (Orgs). Evolução histórica da gestão logística do transporte de cargas. In: Gestão logística do transporte de cargas. São Paulo: Atlas, 2013. p.15-29.

REIS, S. A. dos. Demanda por transporte ferroviário: o caso do transporte de açúcar na malha ferroviária da região centro-sul. Rio de Janeiro: PUCRJ, 2007. Originalmente apresentada como dissertação de mestrado, Universidade Pontifícia Católica do Rio de Janeiro, 2007.

SNIC. Relatório anual 2013. Sindicato Nacional da Indústria do Cimento. 2013. Disponível em: <http://www.snic.org.br/pdf/RelatorioAnual2013final. pdf>. Acesso em: 20 fev. 2016. 